\title{
Key Factors That Influence Consumer Decision to Purchase Electric Scooters
}

\author{
Ying-Wei Wang, I-Shuan Wu, Huan-Chen Kang \\ National Penghu University of Science and Technology, Penghu, Taiwan
}

\begin{abstract}
The study derived 20 variables that influence the decision to buy an electric scooter (ES) based on a literature review and interviews with distributors and customers. These variables were divided into five groups, including government strategy, product strategy, pricing strategy, place strategy, and promotion strategy, and then, a hierarchical structure was established. The weighting of the variables and the relationships among them were obtained using the analytic hierarchy process (AHP) and the decision-making trial and evaluation laboratory (DEMATEL) technique. The results show that product warranty has the highest weighting and is thus the most important variable, with battery capacity (i.e., driving range) the second. Government strategy (including the items of purchasing subsidy, training maintenance personnel, locations of recharging stations, and not imposing fuel and license taxes) is the main factor that influences consumer intentions to purchase ES, and its effects can be strengthened by other factors. Therefore, future marketing strategies to promote the sale of ES should highlight favorable government strategies with regard to this emerging form of transport. That is, government purchasing subsides and the locations of recharging stations are the critical measures that can increase consumer intentions to buy an ES. Moreover, the producers of such vehicles should continually work to improve their driving range and provide good product warranties.
\end{abstract}

Keywords: electric scooters (ES), green transportation, low-carbon island, consumer behavior

\section{Introduction}

In 2011, the Taiwanese government initiated its low-carbon island plan, with the aim of reducing fossil fuel consumption and emissions of greenhouse gases. Penghu Island, which is located off the coast of Taiwan, was selected for development as an example of a low-carbon island. Due to the significant emissions from the transportation sector, green transport is an important part of this plan, and thus many marketing and promotional activities have been undertaken to increase the use of electric scooters (ES) and decrease that of conventional vehicles. For example, the subsidy offered by the local government to purchase an ES that is in accordance with the Taiwan E-scooter Standard (TES) ranges from NT\$24,000 to NT\$34,000, depending on the type of vehicle bought. In addition, the number of registered scooters with conventional engines was limited in 2012, and the use of two-stroke engine scooters will be prohibited on the island in 2014. However, ES sales are still below expectations (at around only 2,000 per year), and thus it is important to identify the key factors that influence consumer decisions to purchase such vehicles.

Ying-Wei Wang, professor, Department of Marketing and Logistics Management, National Penghu University of Science and Technology. Email: ywwang@npu.edu.tw; ywwang@gms.npu.edu.tw.

I-Shuan Wu, master, Institute of Service Management, National Penghu University of Science and Technology.

Huan-Chen Kang, assistant professor, Department of Hospitality Management, National Penghu University of Science and Technology. 
This study employed an integrated method using the analytic hierarchy process (AHP) and the decision-making trial and evaluation laboratory (DEMATEL) technique to explore the key factors that influence the intention to purchase an ES. The results of this work can be used as the basis for future marketing strategies and/or for the improvement of ES design to increase the purchase intentions of potential users.

\section{Method}

The AHP procedure was used to identify the importance of each factor with regard to the overall goal, i.e., increasing the sales of ES, and thus to identify the most critical ones. AHP was first proposed by Saaty (1980), and can be applied to solve multiple-attribute decision-making problems under uncertain conditions. In AHP, the primary problem or goal is broken down into several components. The ratio of scales is then used to compare the relative importance of these and identify the critical factors. However, the causal relationships among the components, as well as their relative strengths, cannot be obtained when using the AHP, and thus the DEMATEL method was used in this work to achieve this. The DEMATEL method was proposed by Fontela and Gabus (1972), and can be applied to solve the complicated social problems that are related to factors such as race, hunger, environmental protection, energy use, and so on. Using this approach, the complicated structure of various cause-effect relationships can be clarified by observing the influences between various pairs of factors. In addition, the resulting causal relationships can be represented simply by using a causal diagram that uses digraphs to portray the basic concepts of the contextual relationships, as well as the strengths of the influences among the various factors or components (Kim, 2006; Roy, Misra, Gupta, Neha, \& Goswami, 2012; Wu \& Lee, 2007). Therefore, the critical factors that affect consumer decisions to purchase ES can be obtained using this integrated method.

Based on a review of the literature and interviews with distributors, the overall goal can be divided into five strategies, including government, product, pricing, place, and promotion ones (Jain, 2000; Schewe \& Hiam, 1999). The government strategy is composed of purchasing subsidy, training maintenance personnel, locating refueling stations, and not imposing fuel and license taxes. The product strategy is divided into seven parts, including driving range, acceleration ability, climbing ability, showing remaining charge, recharging time, model appearance, and after-sale service. The pricing strategy is composed of the sale price and warranty period. The place strategy is composed of convenience of maintenance service, service cost, and product introduction and explanation. The promotion strategy includes customer education, enhancing public awareness of environmental protection and energy saving, sale promotion, and promotions and demonstrations by public sector.

A survey of 30 ES users was undertaken using AHP and DEMATEL questionnaires in April 2011, and the data obtained from these were then analyzed, with the results reported below.

\section{Findings}

The weights of the factors and criteria obtained from the AHP analysis are shown in Table 1, and it can be seen that product strategy is the most important, followed by price and government strategies. With regard to the government strategy, the criterion of refueling station locations is the most important one, followed by the purchasing subsidy. In the product strategy, the recharging time needed and driving range are the most important criteria with regard to purchasing an ES. In the pricing strategy, the warranty period is more important than the sale price. In place strategy, the convenience of maintenance service is the most important criterion. Finally, in the promotion strategy, raising awareness of environmental protection and reduced energy consumption is the key criterion. 
Table 1

Weights of Factors and Criteria

\begin{tabular}{|c|c|}
\hline First-tier dimensions & Second-tier criteria \\
\hline \multirow{4}{*}{ Government strategy (0.2109) } & Purchasing subsidy (0.0448) \\
\hline & Training maintenance personnel (0.0403) \\
\hline & Locating refueling stations (0.0822) \\
\hline & Not imposing fuel and license taxes (0.0436) \\
\hline \multirow{7}{*}{ Product strategy (0.3228) } & Driving range (0.0669) \\
\hline & Acceleration ability (0.0415) \\
\hline & Climbing ability (0.0498) \\
\hline & Showing remaining charge $(0.0268)$ \\
\hline & Recharging time (0.0715) \\
\hline & Model appearance (0.0176) \\
\hline & After-sales service $(0.0486)$ \\
\hline \multirow{2}{*}{ Pricing strategy $(0.2145)$} & Sale price $(0.1005)$ \\
\hline & Warranty period $(0.1140)$ \\
\hline \multirow{3}{*}{ Place strategy $(0.1346)$} & Convenience of service $(0.071)$ \\
\hline & Service cost $(0.0459)$ \\
\hline & Product introduction (0.0177) \\
\hline \multirow{4}{*}{ Promotion strategy (0.1171) } & Customer education (0.0248) \\
\hline & Raising awareness of environmental protection and reduced energy consumption (0.0517) \\
\hline & Sale promotion $(0.0245)$ \\
\hline & Promotions and demonstrations by public sector $(0.016)$ \\
\hline
\end{tabular}

Relational matrix A from the DEMATEL analysis can then be used to identify the total effects (both direct and indirect) given or received by factor $i$ to or from the other factors (Tzeng, Chiang, \& Li, 2007):

$$
A=\left[\begin{array}{lllll}
1.1631 & 1.2987 & 1.3456 & 1.1756 & 1.4047 \\
1.1584 & 0.9500 & 1.0949 & 1.0273 & 1.1674 \\
1.2783 & 1.2168 & 1.0157 & 1.0463 & 1.2660 \\
1.0161 & 0.9977 & 0.9768 & 0.7556 & 1.0692 \\
1.1531 & 1.1311 & 1.0825 & 0.9818 & 0.9923
\end{array}\right]
$$

For example, $r_{1}$ (the sum of the first row values: 6.3877) represents the total effects, both direct and indirect, given by factor $r_{1}$ (government strategy) to the other factors. $c_{2}$ (sum of the second column values: 5.5943 ) shows the total effects, both direct and indirect, received by factor 2 (product strategy) from the other factors.

The sum of $r_{i}+c_{i}$ shows the degree of importance that factor $i$ has in the system. The difference $\left(r_{1}-c_{1}\right)$ shows the net effect that factor $i$ contributes to the system. For example, the sum of $r_{1}+c_{1}$ shows the degree of importance (12.1567) that government strategy plays in the system. The difference of $r_{1}-c_{1}$ shows the net effect (0.6187) that government strategy contributes to the system (it is thus a net cause). Figure 1 shows the impact-relationships map, and it can be seen that government strategy, price strategy, and promotion strategy are the most important factors, and all the related values of $r_{i}+c_{i}$ are greater than 11.1060, and that the government and product strategies are net causes because their values of differences are greater than 0 . Figure 2 shows the impact-relationship map for government strategy, and it can be seen that refueling station locations and purchasing subsidies are not only the key factors but also the net causes. 


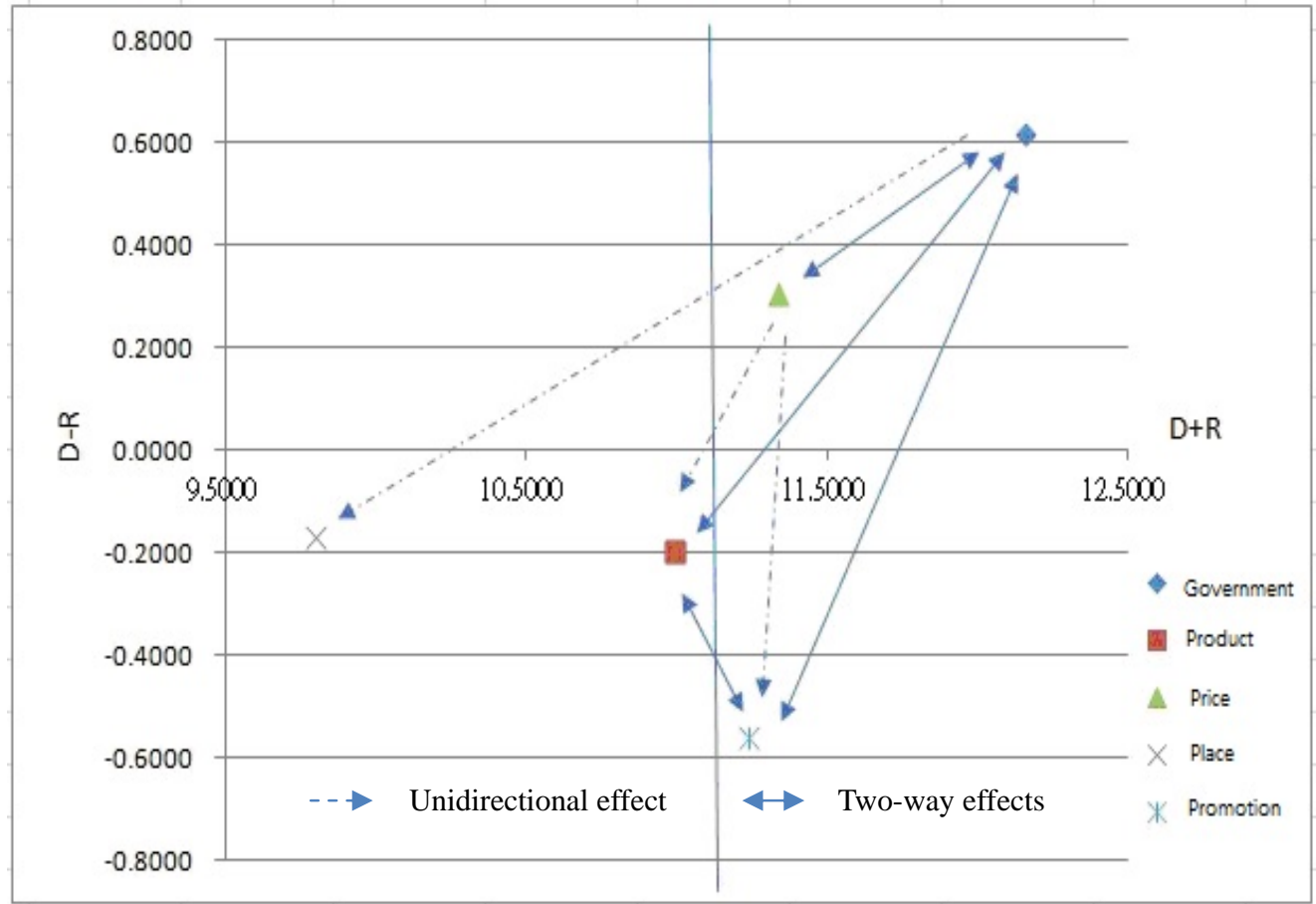

Figure 1. The impact-relationship map (among strategies).

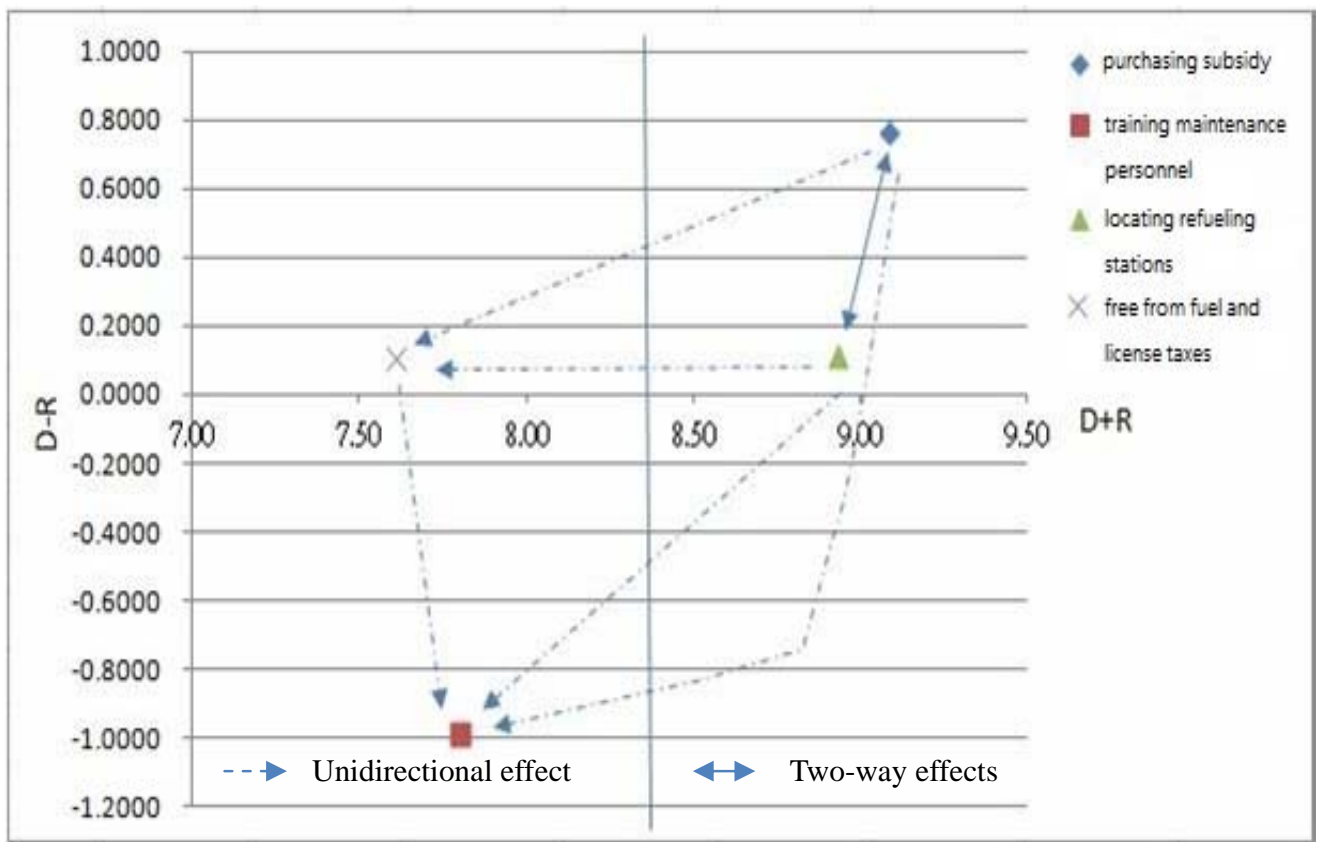

Figure 2. The impact-relationship map (for government strategy).

Based on the results of AHP and DEMATEL, we can see that the government strategy plays an important role in the decision to purchase an ES. Furthermore, refueling station location (i.e., the ease of refueling) and purchasing subsidies are the main factors that enhance consumer intention to purchase an ES. In addition, with regard to product strategy, factors related to performance, such as a longer driving range and shorter recharging, are critical in encouraging the sales of ES. 


\section{Conclusion}

This work applied an integrated method, using both AHP and DEMATEL, to examine the weights of various strategies and criteria with regard to their effects on the decision to purchase an ES, as well as the relationships between each pair of factors or criteria. Overall, the government strategy is the most important one, where purchase subsidies and refueling station locations have the greatest effect on consumer willingness to purchase an ES. Therefore, government policy for the subsidies of ES purchasing can be continued. Government can also make efforts to establish the entire infrastructure environment of ES use. That is, to locate the sufficient refueling stations in the city via circumspect facility planning. In addition, efforts to improve the performance of ES, especially by extending the driving range, shortening the refueling time, and increasing the abilities to accelerate and climb, can also enhance consumer intentions to purchase an ES. Currently, how to position the market of ES use and deploy the optimal locations of the refueling stations is our next step to study.

\section{References}

Fontela, E., \& Gabus, A. (1972). World problems: An invitation to further thought within the framework of DEMATEL. Switzerland Geneva: Battelle Memorial Institute Geneva Research Centre.

Jain, S. C. (2000). Marketing planning \& strategy. Yang-Chih Book Co., Ltd..

Kim, Y. H. (2006). Study on impact mechanism for beef cattle farming and importance of evaluating agricultural information in Korea using DEMATEL, PCA, and AHP. Agricultural Information Research, 15(3), 267-279.

Roy, B., Misra, S., Gupta, P., Neha, \& Goswami, A. (2012). An integrated DEMATEL and AHP approach for personnel estimation. IRACST - International Journal of Computer Science and Information Technology and Security, 2(6), 1206-1212.

Saaty, T. L. (1980). The analytic hierarchy process. New York, NY: McGraw-Hill.

Schewe, C. D., \& Hiam, A. W. (1999). The portable MBA in marketing. New York, NY: John Wiley \& Son, Inc..

Tzeng, G. H., Chiang, C. H., \& Li, C. W. (2007). Evaluating intertwined effects in e-learning programs: A novel hybrid MCDM model based on factor analysis and DEMATEL. Expert Systems with Applications, 32(4), 1028-1044.

Wu, W. W., \& Lee, Y. T. (2007). Developing global managers' competencies using the fuzzy DEMATEL method. Expert System with Applications, 32(2), 499-507. 